\title{
PRÁTICAS EDUCATIVAS AMBIENTAIS FORMAIS: O QUE A ECOPEDAGOGIA PODE CONTRIBUIR
}

Graciele Cristiane Rambo Grenzel ${ }^{1}$

Terezinha Corrêa Lindino ${ }^{2}$

Resumo: Questões relacionadas ao cuidado e preservação do Meio Ambiente têm permeado vários espaços, inclusive o educacional. A escola passa a ter grande relevância no processo de formação e sensibilização dos alunos para assuntos relacionados ao Ambiente, e as práticas educativas ambientais passam a fazer parte do cotidiano dos espaços de ensino. Para tanto, esse artigo tem como finalidade trazer alguns aspectos da Ecopedagogia que podem contribuir para o desenvolvimento de práticas que possibilitem a formação crítica e reflexiva de ações que promovam a formação de novos valores e cuidados com o ambiente. Como metodologia utilizou-se da revisão bibliográfica e análise de um projeto desenvolvido em uma escola no município de Marechal Cândido Rondon - PR, e por fim a discussão da proposta com base na teoria da Ecopedagogia. A realização deste trabalho possibilitou compreender que a proposta da Ecopedagogia tem muito a contribuir para reeducar a visão do aluno frente aos cuidados com o Meio Ambiente e que conservar é muito mais do que a recolha e destinação de resíduos; mas sim, um trabalho de sensibilização para a diminuição de seu uso. E poder assim mudar a relação do homem com a natureza, construindo um futuro sustentável.

Palavras-chave: Práticas Ambientais; Educação Ambiental; Ecopedagogia.

1 Universidade Estadual do Oeste do Paraná. E-mail: graciele.rambo@hotmai.com 2 Universidade Estadual do Oeste do Paraná. E-mail: terezinhalindino@gmail.com 
Abstract: Issues related to the care and preservation of the Environment have permeated several spaces, including the educational one. The school becomes highly relevant in the process of training and raising students' awareness of issues related to the environment, and environmental educational practices become part of the daily life of teaching spaces. To this end, this article aims to bring some aspects of Ecopedagogy that can contribute to the development of practices that enable the critical and reflective formation of actions that promote the formation of new values and care for the environment. The methodology used was the bibliographic review and analysis of a project developed in a school in the municipality of Marechal Cândido Rondon - PR, and finally the discussion of the proposal based on the theory of Ecopedagogy. The accomplishment of this work made it possible to understand that the Ecopedagogy proposal has a lot to contribute to re-educate the student's vision regarding the care with the Environment and that conserving is much more than the collection and disposal of waste; but rather, an awareness campaign to reduce its use. And thus being able to change the relationship between man and nature, building a sustainable future.

Keywords: Environmental Practices; Environmental Education; Ecopedagogy.

\section{Introdução}

O consumo descontrolado deflagra o modo de produção capitalista atual. $\mathrm{E}$, a partir dele, podemos elencar quem são os principais responsáveis pela degradação do meio ambiente e pelo esgotamento dos recursos naturais. Diante desse cenário, a necessidade de se construir um desenvolvimento sustentável torna-se premente. Não é por acaso que vários são os trabalhos que estão sendo realizados sobre esta temática nas últimas décadas.

Desta forma, este trabalho intenta analisar uma prática educativa ambiental realizada no ambiente escolar intitulado: "Pequenos gestos gerando transformações". Mas, cabe ressaltar que a reflexão sobre esta prática visa a contribuir para a construção de um novo olhar sobre o desenvolvimento de práticas educativas, no sentido de que tal prática necessita ir muito além das ações pontuais executadas, trilhando um caminho que conduza o aluno à mudança do seu modo de ver e estar no mundo e, por consequência, a construção de condutas que levem a um futuro sustentável.

Para tanto, este olhar foi desenvolvido em três etapas: primeira, por meio do levantamento bibliográfico sobre o entendimento do que é Educação Ambiental e as formas de colocá-la em prática (por meio das ideias da Ecopedagogia); segunda etapa, a apresentação do projeto e do contexto educacional em que ele foi desenvolvido; terceira, a análise e a discussão da proposta, com base na teoria da Ecopedagogia.

\section{Educação Ambiental e Ecopedagogia: casamento possível?}

Conforme estabelece a Lei 9.795/1999, a Educação Ambiental (EA) é compreendida como qualquer processo que seja capaz de construir individualmente ou coletivamente "[...] valores sociais, conhecimentos, 
habilidades, atitudes e competências voltadas para a conservação do meio ambiente, bem de uso comum do povo, essencial à sadia qualidade de vida $e$ sua sustentabilidade" (BRASIL, 1999). Para tanto, esta lei indica que a EA necessita ser parte integrante "[...] essencial e permanente da educação nacional, devendo estar presente, de forma articulada, em todos os níveis e modalidades do processo educativo, em caráter formal e não-formal' (BRASIL, 1999).

No Brasil, sua importância passou inicialmente pela discussão se ela deveria ou não assumir uma cadeira como disciplina no currículo escolar. Sobremaneira, no início dos anos 2000, o Conselho Federal de Educação optou em rejeitar a ideia, entendendo que a EA deveria permear todas as disciplinas, pois considerou que ela "[...] pode estar presente em todas as disciplinas, quando analisa temas que permitem enfocar as relações entre a humanidade e o meio natural, e as relações sociais, sem deixar de lado suas especificidades" (REIGOTA, 2001, p. 25).

Nesse interim, as ideias da Ecopedagogia, veiculadas por Gadotti (2000), se apresentavam como uma proposta pedagógica que poderia contribuir com a EA na formação de sociedades sustentáveis, dentro de uma perspectiva planetária. Assim, pensar em ações que busquem a construção de uma educação para a sustentabilidade para todos os seres que habitam a Terra e a própria terra, pois a educação para a sustentabilidade, nesta perspectiva, pode contribuir para o processo de reflexão e construção de uma nova conduta que possa levar a um verdadeiro futuro sustentável (PEREIRA et al., 2008).

Ademais, cabe ressaltar que a palavra sustentabilidade tem sido amplamente mencionada e repetida dentro dos movimentos que lutam pela qualidade de vida do planeta, seu cuidado e respeito. E, compartilhando deste mesmo pensamento, a Carta da Ecopedagogia declara que:

A sustentabilidade deve ser um princípio interdisciplinar reorientador da educação, do planejamento escolar, dos sistemas de ensino e dos projetos políticos-pedagógicos da escola. Os objetivos e conteúdos dos currículos devem ser significativos para o(a) educando(a) e também para a saúde do planeta (IPF, 1999, item 03).

Sendo assim, a Ecopedagogia sugere a implantação de um movimento pedagógico que permita a ampliação do "[...] pensamento crítico e inovador, em seus modos formal, não formal e informal, tendo como propósito a formação de cidadãos com consciência local e planetária" (IPF, 1999, item 06). Logo, Gadotti (2000) destaca que como o desenvolvimento sustentável tem um importante componente educativo, no qual "[...] a consciência ecológica e a formação da consciência dependem da educação, é aqui que entra em cena a Ecopedagogia" (GADOTTI, 2000, p. 79). 
Baseada na pedagogia freiriana, tendo sua origem nos estudos de Francisco Gutiérrez, Gadotti (2000) apresenta que os princípios fundamentais da Ecopedagogia são: partir das necessidades dos alunos (curiosidade); promover a relação dialógica professor-aluno; ter a educação como produção e não como transmissão e acumulação de conhecimentos; e, por fim, desenvolver a educação para a liberdade (escola cidadã e pedagogia da autonomia), buscando uma educação que permitisse uma visão mais holística e equilibrada sobre o ser humano e a natureza.

Mas, logo se percebeu que a ideia não teria força necessária para construir a inovação anunciada na teoria da educação. Desta forma, reformulou-se e criou-se então o conceito de Ecopedagogia como forma de "[...] promover a aprendizagem do sentido das coisas a partir da vida cotidiana" (GADOTTI, 2010, p.42), como projeto alternativo global em que a preocupação não estivesse focada apenas na preservação da natureza, mas na construção de um "[...] novo modelo de civilização sustentável do ponto de vista ecológico (...) que implica em uma mudança nas estruturas econômicas, sociais e culturais" (GADOTTI, 2010, p.42).

A Ecopedagogia, assim, não preza apenas com o estabelecimento de uma relação saudável com o Meio Ambiente, mas com o que fazemos em nosso cotidiano para melhorar essa relação. Dessa forma, ela não se opõe à Educação Ambiental (Figura 1).

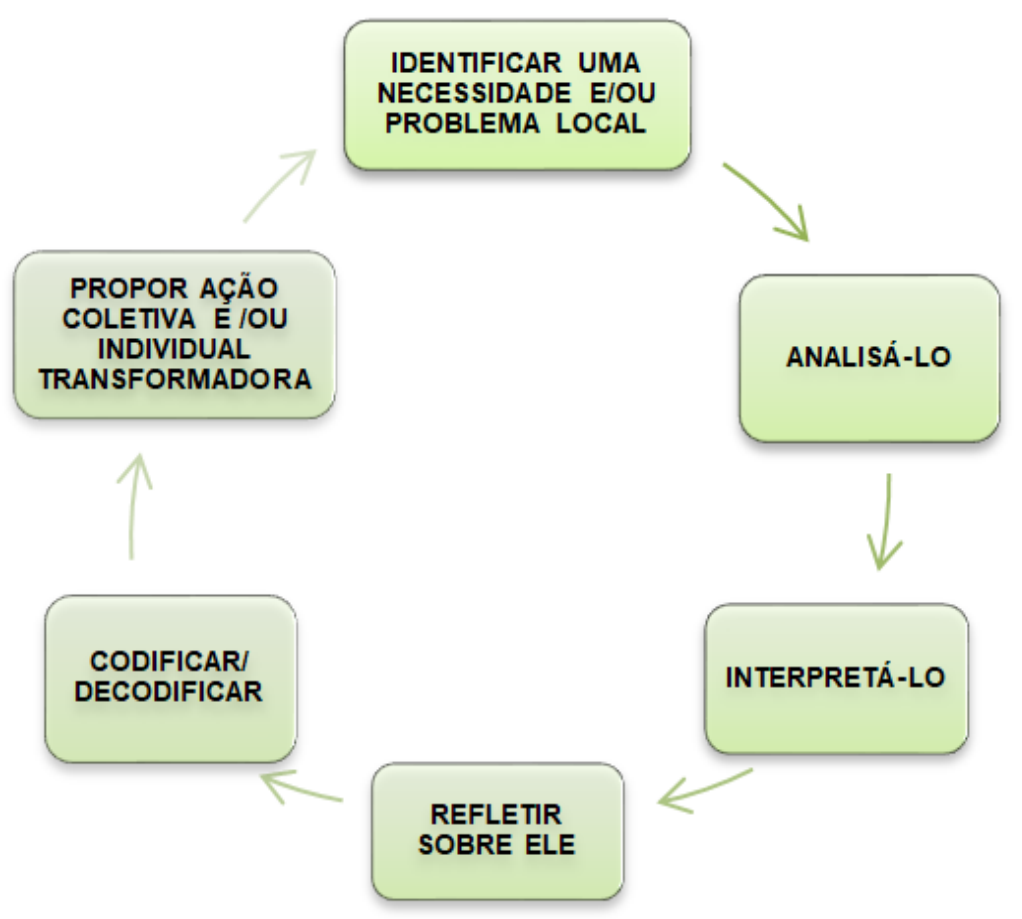

Figura 1: Movimento da Ecopedagogia

Fonte: Elaborado pelas autoras, com base em Gadotti (2000). 
Ao contrário, utiliza-a como pressuposto básico, incorporando e oferecendo "[...] estratégias, propostas e meios para a sua realização concreta" (GADOTTI, 2010, p. 43). A Ecopedagogia suscita a utilização do processo do conhecimento e da busca por soluções para a construção da aprendizagem, dando sentido ao aluno ou ao cidadão envolvido às práticas educativas ambientais executadas, "[...] ultrapassando a visão ambientalista e local, compreendidas dentro de uma visão mais totalizada do mundo" (GADOTTI, 2000, p.183)

\section{Projeto: "Pequenos Gestos gerando transformações"}

A escola A selecionada está localizada no município de Marechal Cândido Rondon, região Oeste do Paraná. Situada na região central da cidade, atende alunos moradores das proximidades e de bairros vizinhos (IBGE, 2018). Atualmente, a escola $A$ atende 488 alunos, sendo estes distribuídos entre turmas de educação infantil, $1^{\circ}$ ao $5^{\circ}$ ano, sala de Classe Especial e, no período noturno, a modalidade de ensino de Educação de Jovens e Adultos (SMED, 2019).

Em seu Projeto Político Pedagógico (PPP) apresenta especial atenção à formação ambiental de seus alunos, pela importância destacada ao trabalho da Educação Ambiental como forma de contribuir para a formação de indivíduos responsáveis e conscientes, quanto ao uso dos recursos naturais e à discussão sobre como o consumismo tem colocada a sociedade em uma situação de risco e de degradação (PPP, 2018).

Dentro de sua proposta pedagógica, o PPP $(2018$, p. 170) da escola A intenta desenvolver "[...] um processo de reflexão e tomada de consciência", no que tange educar e modificar [....] os hábitos e valores dos alunos, como forma de mudar a relação do homem com a natureza" (PPP, 2018, p. 170). Nesse contexto, a missão desta escola busca intervir na educação dos alunos, indo além do ensino de conteúdos, procurando causar a mudança de atitudes em relação aos cuidados com o Meio Ambiente.

A escola $A$, nesse sentido, desenvolve todos os anos projetos de cunho ambiental. Dentre eles, um que tem apresentado grande repercussão dentro do espaço escolar e na sociedade é o projeto "Pequenos gestos gerando transformações" (Figura 2). Este projeto tem por objetivo a coleta de tampas de plástico PP (plástico polipropileno), considerado como a parte mais rígida das embalagens de plástico. 


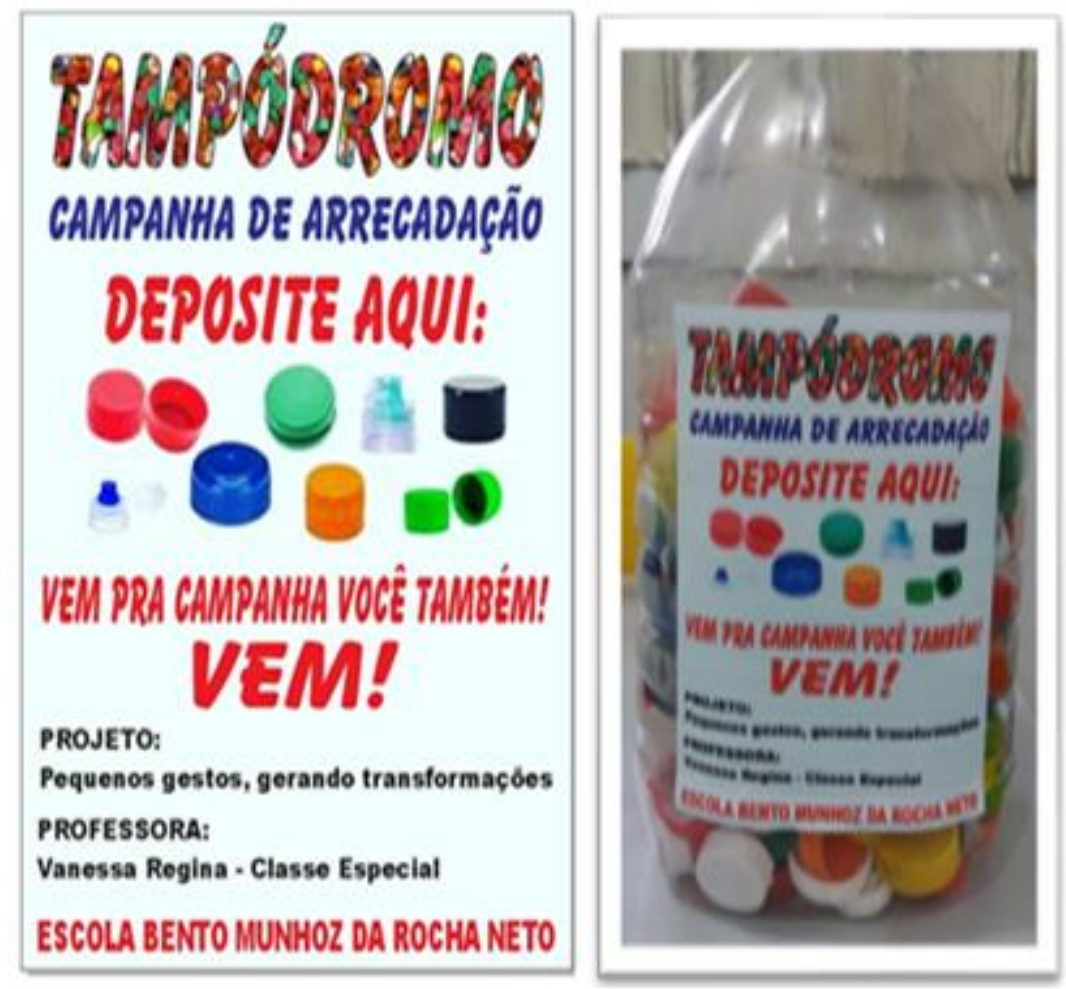

Figura 2: Slogan do Projeto

Fonte: Página da rede social da escola (2019).

Este material, conforme aponta Breves et al. (2015), possui considerável valor agregado e são fontes de matérias-primas para a produção de outros produtos e sua coleta deve ser desmembrada das embalagens que a compõem. Assim sendo, a principal iniciativa do projeto foi a implantação de tampódromos para a arrecadação das tampas e a venda do montante acumulado, sob a justificativa da aquisição de materiais pedagógicos para a escola.

A distribuição dos tampódromos aconteceu dentro do espaço escolar, e cada turma recebeu o seu para armazenar suas coletas. O projeto conta com a parceria de outras escolas, sendo: 03 Centros Municipais de Educação Infantil, 01 Colégio Estadual e 01 Escola municipal localizada no meio rural.

O mesmo aconteceu na comunidade, quando se divulgou o slogan do projeto nas redes sociais e foram espalhados em 20 pontos estratégicos na cidade como: lanchonetes, restaurantes, lojas e mercados; com a implantação de 02 tampódromos itinerantes: 01 no centro da cidade e 01 percorrendo os distritos do município (Figura 3). 


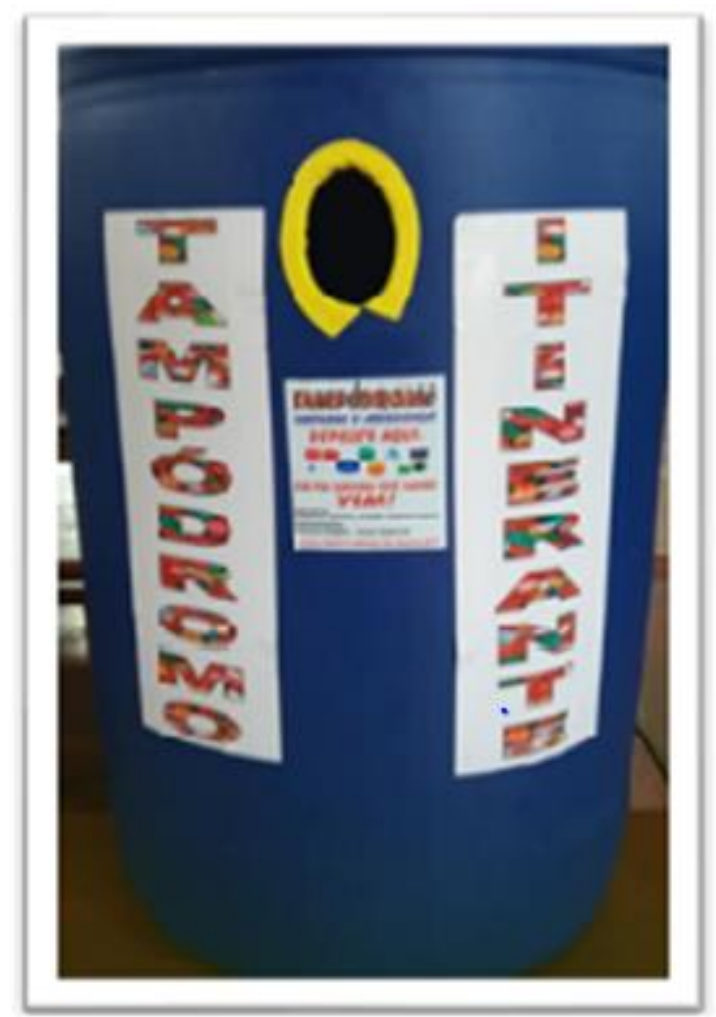

Figura 3: Tampódromo itinerante

Fonte: Página da rede social da escola (2019)

A cada três meses, o montante arrecadado é recolhido e realizada a separação por cores, com o auxílio dos alunos da escola A (Figura 4). Também é pesado e vendido. 


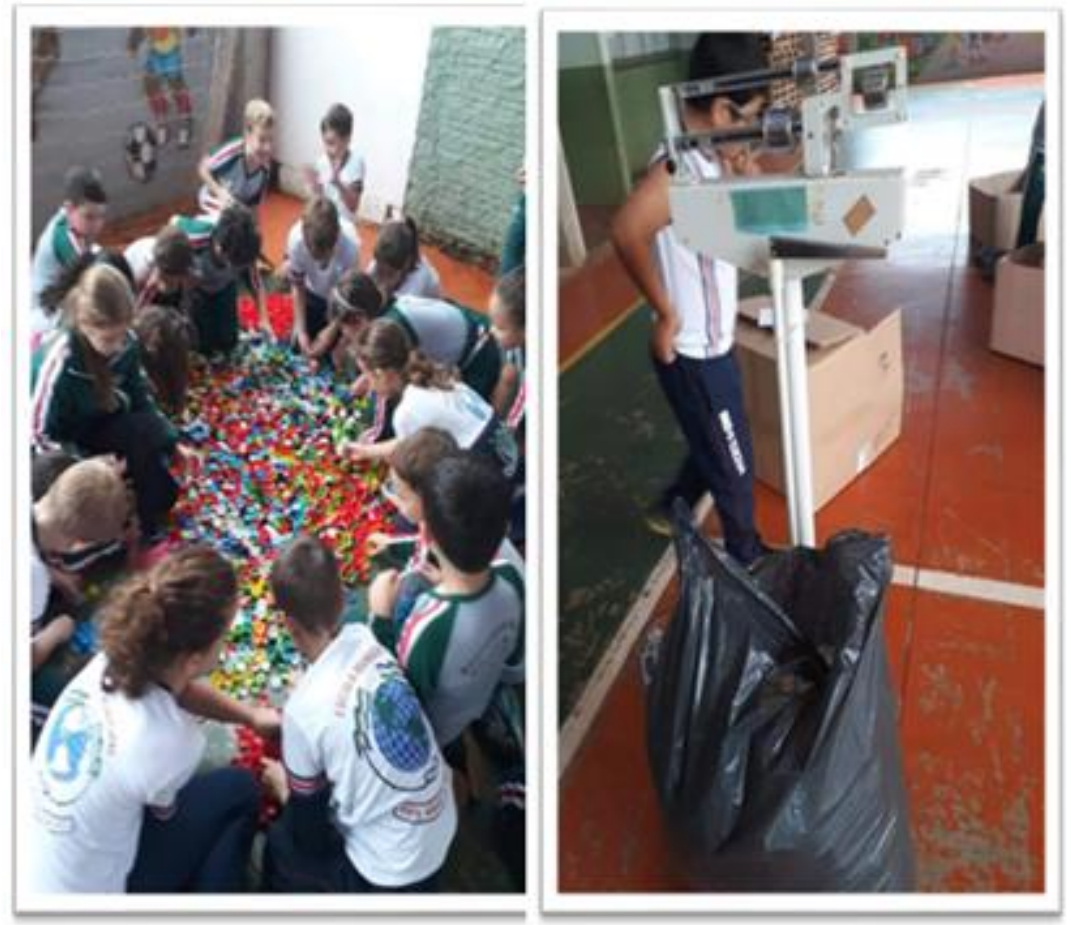

Figura 4: Separação e pesagem das tampas.

Fonte: Página da rede social da escola A (2019).

A proposta do projeto "Pequenos gestos gerando transformações" segue a seguinte execução:

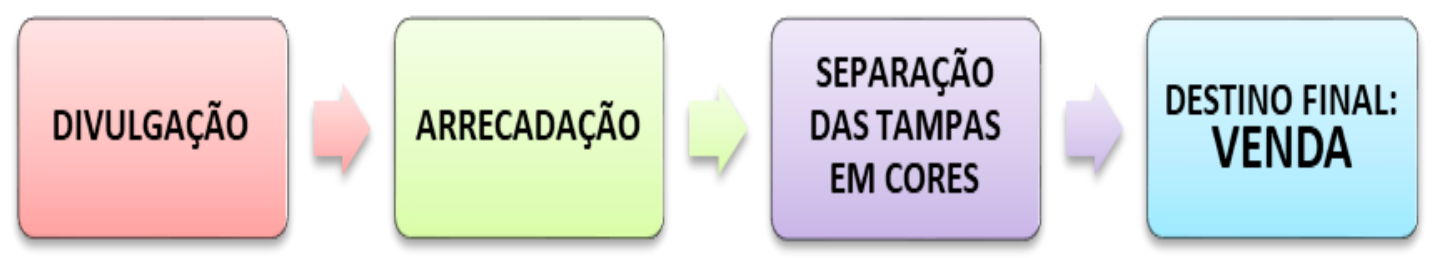

Assim, pensando na importância do papel dos professores no processo de sensibilização dos alunos para assuntos relacionados ao Meio Ambiente, este estudo tem a finalidade de trazer os aspectos da Ecopedagogia que podem contribuir com o projeto analisado. Iniciamos afirmando que para além da coleta e venda de materiais recicláveis, é fundamental a realização de um trabalho que anteceda estas etapas, por exemplo, o consumo consciente e o destino adequado a esse tipo de resíduo.

Para isso, indicamos as ideias contidas na Ecopedagogia, por ser uma proposta pedagógica para a formação de uma sociedade sustentável, assunto este que veremos a seguir. 


\section{Análise e discussão}

Conforme o projeto supracitado, e de acordo com informações levantadas, durante o primeiro trimestre de 2019, realizou-se a primeira venda das tampas. Este período totalizou a quantidade de $165 \mathrm{~kg}$ coletados e foram vendidas para uma empresa que atua na área de injetados plásticos, que utiliza este tipo de matéria-prima na fabricação de copos, grampos de roupa e isolador para cerca elétrica.

Do total coletado, $138,95 \mathrm{~kg}$ eram tampas coloridas e vendidas no valor de $\mathrm{R} \$ 1,50$ o quilo. Também, $26,6 \mathrm{~kg}$ eram de tampas transparentes ou amarelas, com valor de $R \$ 2,00$ o quilo. Diante do valor total resultante ( $R \$$ 261,30), poder-se-ia concluir que economicamente é inviável. Mas, defendemos que este projeto deve ser analisado por outra perspectiva. Começando pela forma que se desenrolou no âmbito escolar.

Nesse sentido, três aspectos chamam à atenção: primeiro, a falta de uma proposta pedagógica para sua realização, pois ao propor o acúmulo de material de determinado resíduo em um ambiente educacional, corre-se o risco de tornar a ação descontextualizada e fragmentada do cotidiano escolar. $\mathrm{Na}$ visão de Gadotti (1998, p. 12), isto "[...] simplifica as coisas e destrói a possibilidade de uma reflexão mais ampla sobre questões da própria sobrevivência da humanidade e do planeta", ao desconsiderar, ou melhor, não dar a devida importância às questões ambientais que permeiam tal ação.

Segundo aspecto, sua ação está dissociada da Proposta Política Pedagógica da escola $A$, no que tange à formação de indivíduos responsáveis e sensibilizados ao uso dos recursos naturais, por meio do entendimento que o consumismo tem colocada a sociedade em uma situação de risco e de degradação.

Terceiro e último aspecto, há concorrência do projeto com o trabalho já realizado pela Cooperativa de Agentes Ambientais de Marechal Rondon Cooperagir, responsáveis pela coleta dos materiais recicláveis no município, formada por catadores que dependem exclusivamente dessa renda. Entendese assim que, a escola ao desenvolver projetos que envolvam a coleta de reciclados torna-se concorrente indireto dos catadores, criando um efeito cascata, pois compromete ainda mais suas condições de subsistência e distancia a escola da sua função formadora.

Ao colocar as crianças e o espaço escolar para trabalhar com a logística reversa do resíduo, como forma de angariar fundos para suprir as necessidades financeiras do dia a dia da escola, pode contribuir para que autoridades compreendam que a escola se autogestiona, comprometendo o orçamento direcionado à Educação. Desta forma, e diante desse cenário, cabe ressaltar o que a Ecopedagogia tem a dizer sobre as práticas ambientais formais.

Conforme consta no próprio título do projeto, ele sugestiona promover transformações aos seus participantes. No entanto, nota-se que as 
transformações promovidas levam a questionamentos simples, e não mudam a realidade de quem questiona. Não há o encaminhamento de respostas a perguntas como: O que significa produzir plástico na atualidade? Que matériaprima é retirada da natureza para sua fabricação? Qual é o tempo de sua decomposição na natureza? Quais são os malefícios produzidos pelo plástico, quando depositados de forma incorreta na natureza? Quais são as novas alternativas de substituição? São inúmeras as perguntas que poderiam ser levantadas, no entanto, são poucas as respostas encontradas.

Observa-se que o projeto estimula o consumo do plástico ao invés de promover sua diminuição, conforme fundamentação apresentada em seu corpo teórico (5R's). Além disso, as transformações às quais o projeto se propõe, estão muito mais voltadas a enfatizar o sistema capitalista vigente (consumismo) do que para ação de cuidado do ambiente (sustentabilidade).

O trilhar desse projeto, na perspectiva da Ecopedagogia, tomaria outro rumo. Ao considerar o reconhecimento da problemática ambiental (plástico), buscar-se-ia formular e executar ações que promoveriam a mudança de posturas "[...] em relação à qualidade de vida e ao Meio Ambiente" (IPF, 1999, item 05). Também identificariam as causas como forma de prevenção, sistematizando a tomada de decisão sobre o que fazer com o plástico.

Assim, desenvolvendo atitudes de observar e evitar a presença de agressões ao Meio Ambiente e aos viventes "[...] para intervir no mundo, no sentido de reeducar o habitante do planeta e reverter a cultura do descartável" (IPF, 1999, item 08). E, em suma, para a Ecopedagogia, o trabalho com resíduos sólidos só teria sentido se fosse capaz de reeducar a visão do aluno para que ele perceba que sua colaboração com o Meio Ambiente não estaria na recolha dos resíduos; mas sim, na diminuição do seu uso. Nesse caso, a quantidade arrecada perde o sentido e o 'menos se tornaria mais'.

\section{Considerações finais}

De acordo com as reflexões realizadas sobre o projeto Pequenos gestos gerando transformações, percebe-se que as práticas educativas ambientais empregadas estão desvinculadas da proposta pedagógica da escola $A$. As ações não desenvolvem a formação desejada de novos valores e cuidados com o ambiente.

Portanto, reiteramos a sugestão do uso das ideias da Ecopedagogia e destacamos a importância de buscar, sempre que possível, partir do interesse do aluno e da problemática ambiental identificada por ele e por seus pares, focando na produção conjunta do conhecimento, visando assim transformar individualmente e coletivamente aquela realidade.

Essa dinâmica possibilita, a quem participa da prática, refletir sobre como sua ação no dia a dia contribui para melhorar sua relação com o meio ambiente, dando sentido à prática realizada e contribuindo com o propósito de 
formar cidadãos com consciência local e planetária. Todavia, não se pode perder o foco de que a proposta é contribuir com os objetivos da Educação Ambiental Formal, servindo de inspiração para que os docentes busquem a realização de práticas educativas ambientais que promovam 0 olhar diferenciado da relação do homem com a natureza.

\section{REFERÊNCIAS}

BRASIL. Lei $n^{\circ} 9.795$, de 27 de abril de 1999. Dispõe sobre a Educação Ambiental, institui a Política Nacional de Educação Ambiental. Brasília.

BREVES, R. R. et al. Avaliação do processo de separação de plásticos descartáveis - polipropileno (PP) e poliestireno de alto impacto (HIPS) - por densidade. Anais do XX Congresso Brasileiro de Engenharia Química, [s.l.], p.01-08, fev. 2015. Editora Edgard Blücher. http://dx.doi.org/10.5151/chemengcobeq2014-0836-23417-144677.

FREIRE, P. A Carta da Terra na educação. São Paulo: Editora e Livraria Instituto Paulo Freire, 2010.

GADOTTI, M. Ecopedagogia e Educação para a sustentabilidade. São Paulo: Instituto Paulo Freire: Universidade de São Paulo, 1998.

GADOTTI, M. Pedagogia da Terra. 6. ed. São Paulo: Petrópolis, 2000.

GADOTTI, M. A Carta da Terra na educação. São Paulo: Editora e Livraria Instituto Paulo Freire, 2010. (Cidadania planetária 3)

IBGE - Instituto Brasileiro de Geografia e Estatística. PAS - Pesquisa Anual de Serviços. [online] Disponível em: https://cidades.ibge.gov.br/brasil/pr/marechalcandido-rondon/panorama. Acesso em: 31 maio, 2018

IPF - Instituto Paulo Freire. Carta da Ecopedagogia: em defesa de uma pedagogia da Terra. São Paulo: Conselho da Terra/UNESCO-Brasil, 1999.

PEREIRA, C. M. M. C. et al. Ecopedagogia: uma nova pedagogia com propostas educacionais para o desenvolvimento sustentável. Etd - Educação Temática Digital, [s.I.], v. 8, n. 2, p.80-89, 3 dez. 2008. Universidade Estadual de Campinas. http://dx.doi.org/10.20396/etd.v8i2.646.

PPP - Projeto Politico Pedagógico: Escola Municipal Bento Munhoz da Rocha Neto. Marechal Cândido Rondon/PR, 2018.

REIGOTA, M. O que é Educação Ambiental. São Paulo: Brasiliense, 2001.

SMED - Secretaria Municipal de Educação de Marechal Cândido Rondon/PR. Documentação Escolar. Fevereiro de 2019. 